\title{
A characteristic cutaneous lesion over the sting site of the wasp, Vespa tropica
}

\author{
E W R A Witharana ${ }^{1}$, S K J Wijesinghe ${ }^{1}$, K S M Pradeepa ${ }^{1}$, W A I P Karunaratne ${ }^{2}$, K M Somarathna ${ }^{1}$
}

Ceylon Medical Journal 2014; 59: 24-25

\section{Introduction}

Hymenoptera stinging may cause cutaneous lesions varying from simple erythema to extensive skin lesions depending on the insect species and type of chemical constitution of their venom [1].

Female hymenopterans have a stinging apparatus which is a modified ovipositor located at the tip of their abdomen and is associated with a venom gland [2]. The stinging apparatus is used in defence if the insect is disturbed. Venom glands of wasps produce a variety of toxic substances including active amines (serotonin, histamine, tyramine, catecholamines), wasp kinins (similar in composition to bradykinins) and histamine-releasing peptides [3]. These toxins cause both local and systemic manifestations, mostly allergy and anaphylaxis after sting. Although multi organ failure, rabdomyolysis, electrocardiographic changes, acute kidney injury and myocardial infarction have been reported rarely, anaphylaxis is the commonest complications associated with hymenoptera sting [3-7].

In Sri Lanka, there are three reported species of wasps belong to the genus Vespa namely Vespa affinis (Linnaeus), V. tropica (Linnaeus) and V. mandarinia (Smith) [8]. Vespa tropica is a tropical species of social wasp found in South East Asia. The worker's length is 19-30 mm with large and thick body covered with strong and stiff hairs. The second gastral tergite is yellow with a slight brown area basally [8]. Recently, four patients with characteristic skin lesions after Vespa tropica stings were admitted to the Base Hospital Deniyaya, Sri Lanka.

\section{Case report}

Four patients with Vespa tropica stinging were admitted to hospital during the period September 2012 to January 2013. The youngest patient was 22 years of age and the oldest was 50 years; three were males. Two victims were stung when they were trying to remove a wasp nest located on the roof of their houses and the other two, while walking on the road. All of them were stung by wasps and the sting was not found over the sting site. Wasp specimens were collected from the four patients and were identified as $V$. tropica (Figure 1).

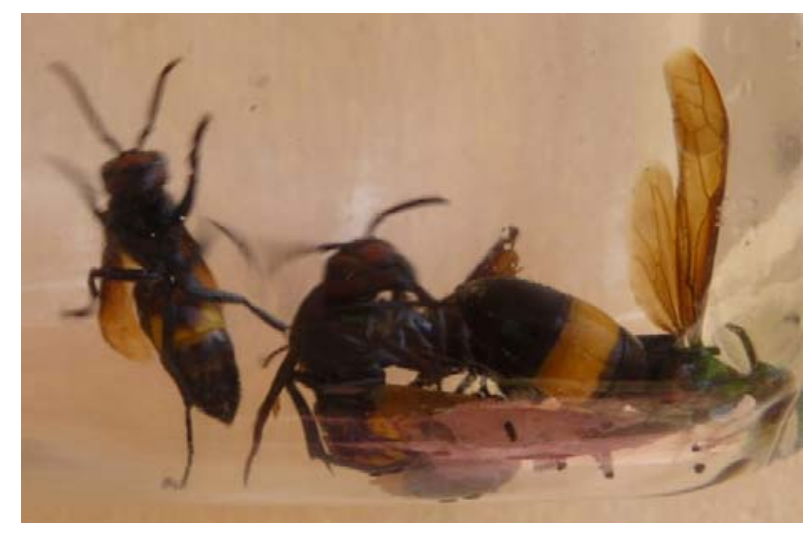

Figure 1. Live specimens of Vespa tropica wasps flying inside a glass chamber.

All victims were stung by less than 10 individual wasps and had pain and swelling over the sting site. Facial puffiness was reported in one patient and two had nausea and vomiting. None developed anaphylactic shock or other complications. The patients were treated with paracetamol, steroids and chlorpheniramine and recovered completely.

One day after the incident a characteristic lesion appeared over the sting site of the patients. All lesions were oval or annular and the area was about $1-2 \mathrm{~cm}$ in diameter. At the centre there was a small yellowish brown vesicle on dark brown necrotic tissue which was slightly depressed from the surrounding skin. The necrotic tissue was surrounded by an oedematous and reddish inflammatory area which was tender. The ulcerated lesion was painful during first few days and later it became itchy and then healed with scar formation (Figure 2).

${ }^{1}$ Base Hospital, Deniyaya and ${ }^{2}$ Department of Zoology, University of Peradeniya, Sri Lanka.

Correspondence: EWRAW, e-mail: <ewrawitharana@yahoo.co.in>. Received 8 August 2013 and revised version accepted 20 October 2013. Competing interests: none declared. 


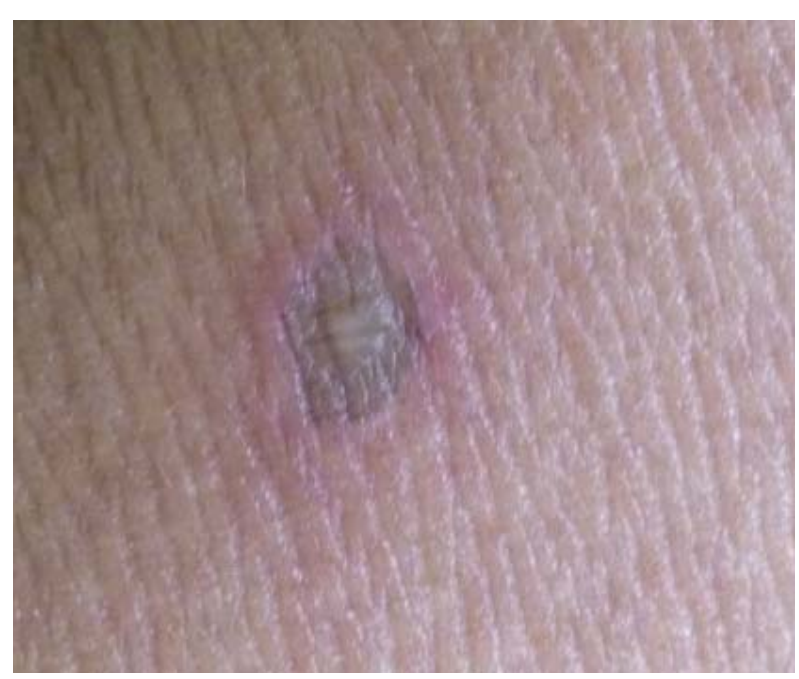

Figure 2. Characteristic skin lesion over the sting site of Vespa tropica.

\section{Discussion}

The cutaneous manifestations of wasp stings are caused by allergic and inflammatory reactions secondary to toxic substances in the venom [2]. Muscles around the venom sac of the wasp inject venom into the victim's skin causing a stinging sensation. This is believed to be due to the presence of acetylcholine and serotonin in wasp venom. Other substances in the wasp venom may stimulate mast cells to release histamine leading to allergic and inflammatory reaction [4]. Common skin reactions after wasp stings are flushing, urticaria and angioedaema [1]. Although extensive swelling and facial puffiness after hymenoptera stings are well described in the past, characteristic skin lesions of Vespa tropica stinging have not been reported. There are few publications on severe multi-organ dysfunction and acute renal failure after Vespa affinis stinging in Sri Lanka but clinical features and skin manifestations of Vespa tropica stinging have not been described [3,6,9].

As most victims of wasp stings present to health care centres with pain and swelling over the sting site, the lesion we describe may help physicians to identify the wasp species as Vespa tropica.

\section{References}

1. Gruchalla RS. Immunotherapy in allergy to insect stings in children. New England Journal of Medicine 2004; 351: 707-9.

2. Theodore M, Freeman MD. Hypersensitivity to Hymenoptera Stings. New England Journal of Medicine 2004; 351: 1978-84.

3. Vetter RS, Visscher PK, Camazine S. Mass envenomations by honey bees and wasps. Western Journal of Medicine 1999; 170: 223-7.

4. Kularatne SAM, Gawarammana IB, De Silva PHJG. Severe multiorgan dysfunction following multiple wasp (Vespa affinis) stings. Ceylon Medical Journal 2003; 48: 146-7.

5. Rowe SF, Greer KE, Hodge RH. Electrocardiographic changes associated with multiple yellow jacket stings. Southern Medical Journal 1979; 72: 483-5.

6. Gunasekera WTP, Mudduwa L, Lekamwasam S. Acute pigmented tubulopathy and interstitial nephritis following wasp sting. Galle Medical Journal 2008; 13: 1.

7. Levine HD. Acute myocardial infarction following wasp sting report of two cases and critical survey of the literature. American Heart Journal 1976; 91: 365-74.

8. Kumar PG, Srinivasan G. Taxonomic studies of hornet wasps (Hymenoptera: Vespidae) Vespa Linnaeus of india. Records of Zoological Survey of India 2010; 110: 57-80.

9. Gunasekara WDVN, Ratnatunga NVI, Abeygunawardena AS. Acute renal failure following multiple wasp bites. Sri Lanka Journal of Child Health 2007; 36: 67-8. 